\title{
FUNGAL CONTAMINATION OF AIRCONDITIONER UNITS IN FIVE HOSPITALS OF ERBIL PROVINCE- KURDISTAN REGION /IRAQ
}

\author{
Salah M. Al-Bader ${ }^{\mathrm{a}, *}$, Layla Q. Ismael ${ }^{\mathrm{a}}$ and Asaad A. Ahmood ${ }^{\mathrm{a}}$ \\ ${ }^{a}$ Dept. of Pathological Analysis, College of Science-Knowledge University, Erbil-Kurdistan Region/Iraq-
}

(salahalbader@yahoo.com)

Received: Jul. 2018 / Accepted: Nov., 2018 / Published: Dec., 2018

https://doi.org/10.25271/sjuoz.2018.6.4.545

\begin{abstract}
:
During April 2018, 75 samples were collected from five hospitals in Erbil city. Samples were taken by sterile cotton swabs from the air dispenser window of air conditioner units (ACU). They were cultured directly on Sabouraud's dextrose agar incubated at $25^{\circ} \mathrm{C} \pm 2$. The samples were collected from five departments in each hospital including out-patient ward (OP), in-patient ward (IP), emergency room (ER), intensive care unit (ICU), and operation theater (OT) A total of (410) fungal colonies were counted. They belong to13 genera include ten hyphomycetes and only one of zygomycetes, basidiomycetes, and hemiascomycetes. Penicillium represented in the highest total occurrence (40\%) followed by Aspergillus (38.66\%) and Alternaria $(21.33 \%)$. The total frequency showed that Candida was the highest (30\%) followed by Penicillium (27.56\%) and Aspergillus (13.17\%). The highest density of filamentous fungi (no. of colony/sample) was detected in $\mathrm{OP}=16.75$, and the lowest in $\mathrm{OT}=1.5$. The diversity of isolates showed that (9) genera were recorded from ER(60\%) and only one in OP (6\%). All recorded genera in current study were regarded as indoor air pollutants. The predominant genera Alternaria, Aspergillus, Penicillium, Cladosporium and Candida are well-known allergens and may cause several pulmonary disorders as well as fetal infections in particular cases.
\end{abstract}

KEYWORDS: fungi, air-conditioner, hospital, asthma, allergy

\section{INTRODUCTION}

Air conditioner units (ACU) have an effective role in buildings air quality whereas the contaminated equipments swell out indoor bio aerosol pollutants particularly airborne fungi (Aligbe et al., 2016; Gniadek \& Macura, 2011). Hazards of such biotic pollutants are more serious in hospital environment than in other buildings (Kelkar \& Kulkarni, 2011) and the long stay in the hospital increase the risk (Khan \& Karuppayil, 2011). Most of airborne fungi which contaminate hospital environment regard as agents of significant respiratory infections (Kelkar, Bal, \& Kulkarni, 2005; Perdelli et al., 2006) and they may be related to sick building syndromes SBS (Pati, 2018). Early work by Arnow in 1978 showed the relation between Aspergillus fumigates colonize ventilation system and apergillosis (Arnow \& Andersen et al., 1978). Nowadays, fungal contamination of buildings environment via (ACU) are widely discussed, and they are used as indicator for indoor air quality (Gniadek \& Macura, 2011; GRBIĆ, VUKOJEVIĆ, et al., 2008; Cabral, 2010). Among several clinical departments, OT acquired the highest interest in studying microbial air pollutants (Kelkar, Bal, and Kulkarni, 2005; Yau, Chandrasegaran, and Badarudin, 2011).

The aims of the present study are: (1) Isolation and identification of fungi contaminated air conditioner units in five wards of five governmental hospitals in Erbil city. (2) Analyzing the fungal community structure. (3) Raising awareness of health hazards of (AC) as a source of contamination.

\section{MATERIALS AND METHODS}

\subsection{Sample collection}

During April 2018, a (75) samples were collected from five governmental hospitals in Erbil city. All samples were taken by sterile moistened swabs from air dispenser window of split type air condition units. The cotton swabs were pressed on the plastic sweepers in 10 deferent points for each air-conditioner (AC). Samples were collected $(9 \mathrm{pm})$ after (12) hours continuous operation of the device. They were collected from emergency room (ER), patients ward (PW), laboratory (L) intensive care unit (IC) and operation theater (OT).

\subsection{Culturing and identification}

Samples were cultured directly on Sabouraud's dextrose agar (SDA)with $150 \mathrm{mg} / \mathrm{L}$ chloramphenicol, the cotton swabs were slightly press of on SDA surface, triplicate were prepared to each sample. Petri-dishes $(90 \mathrm{~mm})$ were incubated in $25^{\circ} \mathrm{C} \pm 2$, and the plates were examined regularly from the fourth day until fourteenth. The mean of colony forming units (CFUs) in triplicate/sample were calculated, and fungal genera were identified based on morphological characteristics (Domsch, Gams, and Anderson, 1980; De Hoog, Guarro, et al., 2000).

\subsection{Fungal community}

The total occurrence, the total frequency, and the prominence value (P.V.) of isolated fungi were calculated as in (Al-Bader, Ahmood, Majeed, Al-Hamdani, 2013):

$\mathrm{TO} \%=($ No. of times fungal appear $* 100) /$ No. of collected samples

$\mathrm{TF} \%=($ No of fungal isolates $* 100) /$ No. of total fungal isolates

$$
\text { P.V. }=\sqrt{F} \times \mathrm{O} \quad(\mathrm{F}: \text { frequency) }(\mathrm{O}: \text { occurrence })
$$

\section{RESULTS}

Among the (75) tested samples, (73) gave a positive result $(97,3 \%)$, and the number of (colonies/plate) ranged from (059). A total of (410) CFU were counted, they belong to (10) genera hyphomycetes $(76 \%)$ and single genus $(7.6 \%)$ to each of zygomycetes, basidiomycetes, and hemiascomycetes (table1). Candida and Rhodotorula the only yeasts developed from samples, the rest isolates were filamentous. Table-1/ Total 
occurrence (TO), total frequency (TF), and prominence value $(\mathrm{PV})$ of fungal isolates in the five hospitals.

Table 1. Total occurrence (TO), total frequency(TF), and prominence value (PV) of fungal isolates in the five hospitals

\begin{tabular}{|c|l|c|c|c|c|c|}
\hline & Fungal genera & $\mathbf{O}$ & $\mathbf{O} \%$ & $\mathbf{T C}$ & $\mathbf{F} \%$ & $\mathbf{P V}$ \\
\hline $\mathbf{1}$ & Acremonium & 2 & 2.67 & 2 & 0.49 & 3.77 \\
\hline $\mathbf{2}$ & Alternaria & 16 & 21.33 & 35 & 8.45 & 94.95 \\
\hline $\mathbf{3}$ & Aspergillus & 28 & 38.6 & 54 & 13.17 & 205.75 \\
\hline $\mathbf{4}$ & Candida & 16 & 21.33 & 123 & 30.00 & 177.44 \\
\hline $\mathbf{5}$ & Cladosporium & 11 & 14.67 & 11 & 2.68 & 36.48 \\
\hline $\mathbf{6}$ & Drechslera & 1 & 1.33 & 25 & 6.10 & 5.00 \\
\hline $\mathbf{7}$ & Mucor & 1 & 1.33 & 1 & 0.24 & 1.00 \\
\hline $\mathbf{8}$ & Paecilomyces & 5 & 6.67 & 12 & 2.93 & 17.32 \\
\hline $\mathbf{9}$ & Penicillium & 30 & 40.00 & 113 & 27.56 & 318.90 \\
\hline $\mathbf{1 0}$ & Pithomyces & 3 & 4.00 & 3 & 0.73 & 5.19 \\
\hline $\mathbf{1 1}$ & Rhodotorula & 2 & 2.67 & 17 & 4.15 & 8.24 \\
\hline $\mathbf{1 2}$ & Sterile mycelia(B\&W) & 8 & 10.6 & 4 & 0.97 & 16.00 \\
\hline $\mathbf{1 3}$ & Trichoderma & 2 & 2.67 & 2 & 0.48 & 3.77 \\
\hline $\mathbf{1 4}$ & Ulocadium & 2 & 2.67 & 8 & 1.95 & 3.77 \\
\hline & Total no. & 127 & & 410 & & \\
\hline
\end{tabular}

Penicillium had the highest O\% (40\%) followed by Aspergillus and Alternaria $(38.66 \%, 21.33 \%)$ respectively . Cladosporium and sterile mycelia with moderate level, and the rest genera showed low O\% (table-1).

The $\mathrm{F} \%$ of isolated genera (table-1) indicted Candida and Penicillium with the highest level followed by Aspergillus $(40 \%, 27.56 \%, 13.17 \%)$ respectively, while the rest have low F\%.

Prominence value showed that Penicillium, Aspergillus, Candida, Alternaria, and Cladosporium had high values (table1)

The relative density RD ( CFU/plate) for only the filamentous fungal isolates showed a large diversity among hospital departments (table -2 ). Out-patient wards had the highest number (16.75/plate ), while the lowest number was recorded in OT (1.5/plate). On the other hand, the number of recognized filamentous genera in each department were listed as (relative diversity RV), are ranged from nine in ER department to only single genus (Cladosporium) in OT (table-2).

Table 2. Relative density (RD), and relative diversity (RV)of filamentous fungi in five hospitals (out poatient $=\mathrm{OP}$ ) $($ emergency room $=\mathrm{ER})($ inpatient ward $=\mathrm{IP})($ intensive care $=\mathrm{IC})$ (operation theater $=\mathrm{OT}$ ).

\begin{tabular}{|l|l|l|}
\hline & R D & R V \\
\hline OP & $16.75=(18)$ & 7 \\
\hline ER & $8.4=(8)$ & 9 \\
\hline IP & $4.08=(4)$ & 5 \\
\hline IC & $2.6=(3)$ & 3 \\
\hline OT & $1.5=(2)$ & 1 \\
\hline
\end{tabular}

\section{DISCUSSION}

During the previous years there was a clear increase in cases of health care associated infections ( HAIS). It is well known that fungi are involved agents of these diseases (CDC-Hospitalized Patients and Fungal Infections). The high ratio of positive samples $(97.3 \%)$ agree with several previous studies it was affected by different factors include time of collection, type of sample and location. It was (38\%) in wet cooling system in Iran (Mosayebi and Eslamirad, et al, 2017) while it (96\%) air samples of OP in Poland (Gniadek and Macura, 2011). The isolated fungi from (AC) in the current study are common as outdoor airborne (Ramddn and Salih, 2010; Al-Bader, 1992) and their relation with respiratory infections is quietly known (Al-Bader, Ahmood, Majeed, and Al-Hamdani, 2013; Curtis,
Liberman, Stark, and Veter, 2004). Penicillium, Aspergillus, Candida, Alternaria, and Cladosporium had highest (PV) in tested samples, in addition to Mucor and Trichoderma among the most common indoor airborne fungi (Kurup, Der Shen, and Banerjee, 2000). Breathing their spores or vegetative structures cause hazardous effects to human respiratory system (Curtis L, Liberman, Stark, and Veter, 2004; Visagie, Houbraken, 2014). The recorded genera with high PV in this study were documented as allergies and cause several hygienic disorders:

Penicillium: The genus include (354) accepted species (Visagie, Houbraken, 2014; Samson, Uztan, et al., 2017): it is an aero-allergen contaminated hospital environments, and had been commonly isolated from (AC) (GRBIĆ, VUKOJEVIĆ, et al, 2008; Gniadek, and Macura, 2011; Samson and Uztan, et al., 2017; Claudia and de Menezes, et al., 2004). A (16) species produce different types of mycotoxins which in cooperate with polypeptides in getting asthma and rhinitis (Curtis, Liberman, Stark, and Veter, 2004) [20]. The high occurrence and frequency of Penicillium in current study indicate its hygienic impact in hospital environment.

Aspergillus: A cosmopolitant, highly active genus, develop on many substrates in different environments. At least 10 species from 250 related to Aspergillus are mycotoxin producers [20]. In the current study, we recorded five common species which were reported as factors of respiratory allergy. Aspergillus is predominant in outdoor and indoor air samples, and it was documented as the highest occurrence in hospitals environment (Gniadek, and Macura, 2011; Caggiano and Napoli et al., 2014; Klich, 2006). Several species are a common cause of human pulmonary disorders due to mycotoxins and other chemicals which were produced by Aspergilli (Klich, 2006; Castillo et al, 2016). The xerophile and the wide temperature range of growth of Aspergillus support fungus to be one of the most serious indoor air fungi.

Alternaria: A dematiaceous hyphomycetes has $40-50$ species commonly isolated from plants, soil, and indoor air .The most frequent species A.alternata develop in humid indoor environment. Its spores and mycelia produce allergen agents (mycotoxins) that cause rhinitis and asthma (Sara andTereza, et al., 2001).

Candida: An ascomycetous, normal flora yeast that produce airborne spores as blasto conidia ,it occur in indoor air samples of particular environments (Wang et al, 2007). The genus is among the most frequent airborne fungi in hospital environment (Awosika, Olajubu, and Amusa, 2012), and there is an early document explain its relation with chronic asthma and rhinitis (Allergy, 1987; Cordeirol, Raimunda, Brilhantel, Pantoga, Renato, and Filho et at., 2010).

Cladosporium: A dematiacious, common airborne, and surface plant associated hyphomycetes. As Aspergillus and Alternaria, it is rarely devoid of aerobiological studies. The genus is one of the predominant isolates in hospitals (GRBIĆ and VUKOJEVIĆ et al., 2008). Its health disorders were widely documented as well as the toxicity hazard (Curtis, Liberman, Stark, and Veter, 2004; Khan and Karuppayil, 2012).

Paecilomyces: A hyaline hyphomycetes occur commonly as indoor airborne, it was documented in hospital environment as well as other indoor air samples (Khan and Karuppayil, 2012; Airaudi and Marchisio, 1996). Beside the hyalohyphomycosis, Paecilomyces is an accidental agent of several types of respiratory diseases (Strelyaeva, Svistunov, Dzhomaa, and Sapozhnikov et al., 2015).

Rhodotorula: The Basidiomycetous yeast is a member of normal flora on human skin, and can easily be isolated from soil, water, and food. Even though it was documented as one of indoor air pollutants (Khan and Karuppayil, 2012), but its risk on respiratory system was either unrecorded or rare (Twaroch, Curin, Valenta, and Swoboda, 2015; Hasanin, Fatima, AlFrayh, Al-Sedairy, 2005). 
Drechslera, Pithomyces, and Ulocladium: A dematiaceous, hyphomycetes were mostly recorded in immune compromised patients. They are an aerobiological indoor pollutants, and consider as rare pulmonary allergens (Cordeirol, Raimunda, Brilhantel, Pantoga, Renato, and Filho et at., 2010; Khan, Haleem, Mohan, and Karuppayil, 2012). A skin prick test of several asthma and allergy patients showed positive results related to Drechslera and Ulocladium allergens (Menezes E A, Gambale, Macedo, Castro, Paula, and Croce, 1998; Polizzi, Adams, Picco, Adriaens, Lenoir, Peteghem, De Saeger, and De Kimpe, 2011; Perdomo, Sutton, García, Fothergill, Cano, Gené, Summerbell, Rinaldi, and Guarro, 2011). Pithomyces had been isolated from respiratory specimens that suggest its probable impact as allergic agent (De Hoog and Guarro et al. 2000).

The hyphomycetes Trichoderma, and Acermonium beside Mucor the zygomycetes were uncommon in current study but they are well known airborne indoor and outdoor fungi, they were regarded as life threat agents to immuncompromised patients. Several previous studies mentioned their hygienic importance as (Juan F Fernandez, Diego J Maselli, Tamara Simpson, and Marcos I Restrepo, Pulmonary Mucormycosis: What is the best strategy for therapy? Respir Care) which mentioned the relation between SBS and Tricoderma volatile secretions, and the work about Acremonium infections in USA (Hasanin, Fatima, Al-Frayh, and Al-Sedairy, 2005). Mucor was widely described as rare but serious agents of several mucormycosis including lung and respiratory tract (Polizzi, Adams, Picco, Adriaens, Lenoir, Van Peteghem, De Saeger, and De Kimpe, 2011).

\section{CONCLUSIONS}

1- The recognized fungi are opportunistic pathogens, and their hygienic impact increases in hospital environment.

2- Fungi which had been isolated from external part of airconditioner units were highly divers. Hospitalized patients, staff, and workers are at risk for getting fungal infection, no doubt, such expected harms increase positively with time spending inside the building and with immune depression.

3- Because ACU provides a suitable environment for fungal growth, a periodical cleaning of devices should not be ignored and a suitable and safe antifungal can be used to minimize contamination.

4- Much attention should be taken to the AC filters, dust and moisture of these parts induce growth and propagation of airborne fungi.

\section{REFERENCES}

Airaudi D, Marchisio VF.1996.Fungal biodiversity in the air of Turin. Mycopathologia , 136, 95-102.

Al-Bader s. M. The fungal airspora at Basrah - Iraq. Basrah. J. sciences , vol.13, Nol, (11-18) (1992).

Al-Bader, S.M., Ahmood, A.A., Majeed M. Al-Hamdani, M.M. 2013 The Relation between Fungi Isolated from Higher Respiratory Tract of Allergic and Asthmatic Patients, and Air Fungi in their Residence 24(2) 1-12.

Aligbe, D.S., Gide Suleiman, G. and Warodi, F.A 2016. Studies on Microorganisms Associated with Air-Conditioned Environments IOSR Journal of Environmental Science. Toxicology and Food Technology (IOSR JESTFT), 10(7)2319-2402.

Allergy, A.1987. Chronic asthma and rhinitis due to Candida albicans, Epidermophyton, and Trichophyton. 59(1):48-51.

Arnow, P.M., Andersen, R.L., et al 1978. Pulmonary Aspergillosis during Hospital Renovation. American Review of Respiratory Disease, 118.1.49.
Awosika, S., Olajubu, F. and Amusa, N. 2012. Microbiological assessment of indoor air of a teaching hospital in Nigeria, Asian pacific journal of tropical biomedicine, 2(6): 465468.

Cabral, J.P.S., 2010. Can we use indoor fungi as bioindicators of indoor air quality? Historical perspectives and open questions. Science of the total environment 408 (20), 4285-4295.

Caggiano, G. Napoli, C., et al. 2014. Mold contamination in a controlled hospital environment: a 3-year surveillance in southern Italy. BMC Infectious Diseases, 14:595.

CDC-Hospitalized Patients and Fungal Infections.

Claudia Ross, C. de Menezes, J.R., et al. 2004. Studies on Fungal and Bacterial Population of Airconditioned Environments. Brazilian Archives of Biology and Technology, 47(5)827835.

Curtis L, Liberman A, Stark M, Veter M. 2004. Adverse Health Effects of Indoor Molds. Journal of Nutritional \& Environmental Medicine, 14(3), 261-274.

De Hoog, G.S., Guarro, J., et al. 2000. Atlas of Clinical Fungi. Centraalbureau voor Schimmelcultures, Utrecht, The Netherlands. doi: 10.17116/terarkh201587353-58

Domsch, K.H., Gams, W., and Anderson, T.H. 1980." Compendium of Soil Fungi". Academic Press, London, (1)859.

Gniadek, A. and Macura, A.B. 2011. Air-conditioning vs. presence of pathogenic fungi in hospital operating theatre environment. Wiadomooeci Parazytologiczne 257(2), 103-106.

Gniadek, A. and Macura, A.B. 2011. Polish Parasitological Society Air-conditioning vs. presence of pathogenic fungi in hospital operating theatre environment 57(2), $103-106$

GRBIĆ, M.L., VUKOJEVIĆ, J., et al 2008. Fungal Colonization of Air-Conditioning System. 60 (2), 201-206.

Hasanin S M, Fatima K, Al-Frayh, Al-Sedairy S T,2005.Oneyear pollen and spore calendars of Saudi Arabia Al-khobar, Abha and Hofuf. Airobiology 21(3): 241-7.

Juan F Fernandez, Diego J Maselli, Tamara Simpson, and Marcos I Restrepo, Pulmonary Mucormycosis: What is the best strategy for therapy? Respir Care.; 58(5): 60-63.

Kelkar, U. Kulkarni, S. 2011. Contaminated air conditioners as potential source for contaminating operation theatre environment. International journal of infection control. 8: 45-8.

Kelkar, U., Bal, A.M., and Kulkarni, S., 2005. Fungal contamination of air conditioning units in operating theatres in India .Journal of Hospital Infection, 60, 81-84.

Khan AA Haleem, Mohan S. Karuppayil.2012. Fungal pollution of indoor environments and its management. Saudi journal of biological science.19:405-425.

Khan, A.A.H.,and Karuppayil, S.M., 2011. Practices contributing to biotic pollution in Airconditioned indoor environments. Aerobiologia 27, 85-89.

Klich, M.A. 2006. Identification of clinically relevant aspergilli. Med. Mycol, 44,127-131.

Kurup, V.P., Der Shen, H. and Banerjee, B. 2000. Respiratory fungal allerg. Microbes and Infection 2(9):1101-1110.

Menezes E A, Gambale W, Macedo M S, Castro F, Paula C R and Croce J.1998. J.Investig. Allergol. Clin. Immunol.8(4):2148.

Mosayebi a, M., Eslamirad a, Z., et al 2017. Evaluating of fungal contamination in hospital wet cooling systems in Markazi province, Central Iran 27(3)334-338.

Nancy I.Castillo ,MaríaIbáñez Eduardo Beltrán Jhon Rivera-Monroy Juan CamiloOchoa MónicaPáezCastillo Martha L.PosadaBuitrago Michael Sulyok FélixHernández. 2016. Identification of mycotoxins by UHPLC-QTOF MS in airborne fungi and fungi isolated from industrial paper and antique documents from the Archive of Bogotá.

Pati, P. 2018. Review on Common Microbiological Contamination Found in Hospital Air. Journal of Microbiology and Pathology, 2(1): 103

Perdelli, F., Cristina, M.L. et al. 2006. Fungal Contamination in Hospital Environments. Infection Control and Hospital Epidemiology, 27, 44-47.

Perdomo H , D. A. Sutton, D. García , A. W. Fothergill , J. Cano ,J. Gené, R. C. Summerbell, M Rinaldi and J. Guarro. 2011. Spectrum of Clinically Relevant Acremonium Species in the United States Journal of clinical microbiology - vol. 49 . $1.243-256$

Polizzi, V., Adams, A., Picco, A.M., Adriaens, E., Lenoir, J., Van Peteghem, C., De Saeger, De Kimpe, N., 2011.Influence of 
environmental conditions on production of volatiles by Tricho - derma atroviride in relation with sick building syndrome. Building and Environment 46, 945-954.

Ramddn A.Ramadan and Nadhira S. Salih(2010).Isolation and identification of airborne fungi and their relation to allergic diseases in Sulaimania city. MSc thesis 109.

Rossana A Cordeirol, Raimunda S N, Brilhantel, Lydia D M Pantoga,Renato,E Moriera Filho et at. 2010. Isolation of pathogenic yeast in the air from hospital environment in the city of Fortaleza ,Northeast Barazil. Baraz.J.Infec.Dis. 14(1), 30-34.

Samson, R.A., Uztan, A.H., et al. 2017. Indoor airborne fungal pollution in newborn units in Turkey. Environmental Monitoring and Assessment, 189:362.

Sara, H.D., Tereza, Z.M., et al. 2001. Clinical Importance of Alternaria Exposure in Children. American journal of respiratory and critical medicine, 164, 3 .
Strelyaeva AV, Svistunov AA, Dzhomaa RA, Sapozhnikov SA, et al.2015. Pulmonary paecilomycosis: Diagnosis and treatment. Ter Arkh. ;87(3):53-58

Teresa E Twaroch, Mirela Curin,1 Rudolf Valenta,Ines Swoboda.2015. Mold Allergens in Respiratory Allergy: From Structure to Therapy Allergy Asthma Immunol Res.;7(3):205-220.

Visagie, C.M., Houbraken, J. 2014. Identification and nomenclature of the genus Penicillium. Study in Mycology, 78: 343-371.

Wang, Y I, Lu,G., Ma, R. and Chai T.2007. Biodiversity and concentration of airborne fungi in chicken house. ISAH 2007,Tartu,Esonia. www.cdc.gov/fungal/infections/hospitalized.html $564-569$

Yau, Y.H., Chandrasegaran, D., and Badarudin, A., 2011. The ventilation of multiple-bed hospital wards in the tropics: a review. Building and Environment 46 (5), 1125-1132. 